\title{
Prevalence of Metabolic Syndrome Among the End-Stage Renal Disease Patients on Hemodialysis
}

\author{
Khaled A. Alswat ${ }^{\mathrm{a}, \mathrm{e}}$, Awwadh Althobaiti ${ }^{\mathrm{b}}$, Khulod Alsaadic, Amaal Saeed Alkhaldic, \\ Maryam Mutlaq Alharthic, Walaa Abduraheem Abuharbac ${ }^{\mathrm{c}}$, Ahmed A. Alzaidi ${ }^{\mathrm{d}}$
}

\begin{abstract}
Background: Patients with metabolic syndrome (MetS) have a 2.6fold greater risk of incident chronic kidney disease (CKD). The primary goal of this study was to assess the prevalence of MetS in patients with end-stage renal disease (ESRD) who are on hemodialysis (HD) and the impact of MetS presence on HD-related outcomes.
\end{abstract}

Methods: This is a cross-sectional study conducted in the Dialysis Center, King Abdulaziz Specialist Hospital, Taif, Saudi Arabia. It was conducted among ESRD patients that attended the Dialysis Center between August 2013 and September 2016. We excluded patients on peritoneal dialysis and those $<18$ years old. We used the International Diabetes Federation (IDF) criteria to identify patients with MetS.

Results: A total of 241 patients with ESRD on HD were found, with a mean age of 48.8 (SD 16) years, mean body mass index (BMI) of 25.6 (SD 8.7) $\mathrm{kg} / \mathrm{m}^{2}$, and mean waist circumference (WC) of 92.0 (SD 23.5) $\mathrm{cm}$. The mean duration of the HD was 69.3 (SD 65.6) months with arteriovenous fistula (AVF) as the most common access for HD. Of the patients, $38.2 \%$ had MetS. Compared to those without MetS, those with MetS were more likely to be older $(\mathrm{P}<0.001)$, be female $(\mathrm{P}<0.001)$, be married $(\mathrm{P}<0.001)$, have higher $\mathrm{BMI}(\mathrm{P}<0.001)$, have larger WC $(\mathrm{P}<0.001)$, have T2D and hypertension (HTN) $(\mathrm{P}<$ $0.001)$, have shorter HD duration $(\mathrm{P}<0.001)$, have a longer duration since the AVF was placed $(\mathrm{P}=0.026)$, and have high post-HD creatinine levels $(\mathrm{P}=0.010)$ and were less likely to have adequate HD (P $=0.004)$ and have parathyroid hormone $(\mathrm{PTH})$ at goal $(\mathrm{P}=0.046)$.

Conclusion: MetS is common among ESRD and MetS was associated with more comorbidity, worse anthropometric measures at baseline, and worse HD-related outcomes. The limitations were small sample size and single center.

Keywords: Metabolic syndrome; End-stage renal disease

Manuscript submitted April 27, 2017, accepted June 6, 2017

aDepartment of Medicine, Taif University, Taif, Saudi Arabia bepartment of Surgery, King Abdulaziz University, Jeddah, Saudi Arabia 'Department of Medicine, Taif University, Taif, Saudi Arabia

dKing Abdulaziz Specialist Hospital, Taif, Saudi Arabia

${ }^{e}$ Corresponding Author: Khaled A. Alswat, Department of Internal Medicine,

Taif University School of Medicine, Taif, Saudi Arabia.

Email: a.a.althobaiti@hotmail.com

doi: https://doi.org/10.14740/jocmr3064w

\section{Introduction}

End-stage renal disease (ESRD) is the final stage of chronic kidney disease (CKD), in which the kidneys no longer function well enough for the patient to live without medical aid. Common disorders that cause ESRD include type 2 diabetes (T2D), hypertension (HTN), glomerulonephritis, and interstitial nephritis [1]. In the UK, 482 CKD patients per million were kept alive by renal transplants at the end of 2013, and over 115 new patients per million of the adult population are accepted for long-term dialysis treatment each year [2]. The incidence of ESRD is much higher in some countries due to differences in regional and racial incidences of disease, as well as differences in medical practice.

Metabolic syndrome (MetS) is the name for a combination of risk factors that increases the risk for heart disease, diabetes, and stroke. The impact of MetS on the kidney is related to many complications, but the critical one is chronic renal failure with consequent ESRD [3]. MetS prevalence, as defined by the adult treatment panel III (ATP III) criteria, among the 8,841 American adults who participated in the third National Health and Nutrition Examination Survey (NHANES) was 22\% [4]. The Chronic Renal Insufficiency Cohort (CRIC) Study included a group of men and women aged $21-74$ years with renal disease and showed that participants with MetS were more likely to present with a lower estimated glomerular filtration rate (GFR) than those without MetS [5, 6].

In an effort to assess the relationship between MetS and CKD, Chen et al studied and analyzed a group of 7,800 participants in the NHANES III with normal renal function for $>21$ years. They concluded that participants with MetS were at a 2.6-fold greater risk of incident CKD. Also, they found that the risk of CKD increased with the number of MetS risk components, from an odds ratio (OR) of 1.89 in adults with one MetS risk component to 5.85 in adults with all five risk components [7]. A retrospective study on a sample of 60,921 healthy Korean adults showed a higher prevalence of CKD in participants with MetS (11.0\%) than those without MetS $(6.3 \%)$, and the prevalence increased with the number of MetS risk factors [8].

Using the International Diabetes Federation (IDF) criteria to diagnose MetS instead of the ATP III resulted in a higher prevalence of MetS. A nationwide Iranian study showed that the prevalence of MetS was about $34.7 \%$ based on the ATP III criteria and $37.4 \%$ based on the IDF definition [9]. Also, in the same study, the prevalence was highest among older urban 
Table 1. Baseline Characteristics of the Whole Cohort

\begin{tabular}{|c|c|}
\hline \multicolumn{2}{|l|}{ Baseline characteristics $(\mathrm{N}=\mathbf{2 4 1})$} \\
\hline Mean age (years) & $48.8 \pm 16$ \\
\hline Male $(\%)$ & 48.3 \\
\hline Married (\%) & 70.5 \\
\hline High school degree or less (\%) & 40 \\
\hline Mean dry weight (kg) & $62.9 \pm 17.6$ \\
\hline Mean BMI $\left(\mathrm{kg} / \mathrm{m}^{2}\right)$ & $25.6 \pm 8.7$ \\
\hline Mean waist circumference $(\mathrm{cm})$ & $92.0 \pm 23.5$ \\
\hline Mean SBP (mm Hg) & $136.4 \pm 25.1$ \\
\hline Mean DBP (mm Hg) & $76.1 \pm 14.8$ \\
\hline Mean pulse rate (bpm) & $81.7 \pm 12$ \\
\hline Diabetes $(\%)$ & 26.9 \\
\hline Hypertension (\%) & 67.8 \\
\hline Hyperlipidemia (\%) & 21 \\
\hline History of myocardial infarction (\%) & 8.7 \\
\hline Heart failure $(\%)$ & 5.0 \\
\hline History of blood transfusion (\%) & 64 \\
\hline \multicolumn{2}{|l|}{ Medications } \\
\hline Beta-blocker $(\%)$ & 16.4 \\
\hline ACEi/ARB (\%) & 13.4 \\
\hline Calcium channel blocker (\%) & 47.5 \\
\hline Hydralazine $(\%)$ & 6.3 \\
\hline Cholecalciferol (\%) & 7.6 \\
\hline Cinacalcet $(\%)$ & 31.9 \\
\hline Calcium carbonate $(\%)$ & 76.5 \\
\hline Sevelamer $(\%)$ & 52.9 \\
\hline Active vitamin D (\%) & 58.0 \\
\hline Statin $(\%)$ & 19.1 \\
\hline \multicolumn{2}{|l|}{ Dialysis data } \\
\hline Mean duration of dialysis (months) & $69.3 \pm 65.6$ \\
\hline Permacath as an access for HD (\%) & 21.5 \\
\hline Temporary HD access $(\%)$ & 5.4 \\
\hline AVF as an access for HD (\%) & 73.1 \\
\hline$\geq 2$ AVF placed for HD $(\%)$ & 28.7 \\
\hline Mean duration of AVF (years) & $1.8 \pm 1.4$ \\
\hline$\geq 2$ missed dialysis session in the previous 3 months $(\%)$ & 50 \\
\hline$\geq 2$ urgent dialysis in the previous 6 months $(\%)$ & 66.7 \\
\hline History of line infection (\%) & 35.8 \\
\hline PTH at goal $(\%)$ & 22.5 \\
\hline \multicolumn{2}{|l|}{ Laboratory data } \\
\hline Mean total cholesterol (mg/dL) & $145.3 \pm 40.8$ \\
\hline Mean LDL (mg/dL) & $89.7 \pm 7$ \\
\hline Mean HDL (mg/dL) & $38.2 \pm 13.6$ \\
\hline Mean triglyceride (mg/dL) & $145.4 \pm 105.2$ \\
\hline Mean total Ca (mg/dL) & $8.7 \pm 1.2$ \\
\hline Mean phosphate (mg/dL) & $6.3 \pm 7.2$ \\
\hline Mean PTH $(\mathrm{pmol} / \mathrm{L})$ & $57.3 \pm 76.5$ \\
\hline
\end{tabular}


Table 1. Baseline Characteristics of the Whole Cohort - (continued)

\begin{tabular}{|c|c|}
\hline \multicolumn{2}{|l|}{ Baseline characteristics $(\mathrm{N}=\mathbf{2 4 1})$} \\
\hline Mean pre-HD creatinine(mg/dL) & $14.9 \pm 25.3$ \\
\hline Mean post-HD creatinine $(\mathrm{mg} / \mathrm{dL})$ & $5.7 \pm 7.5$ \\
\hline Mean post-HD urea (mg/dL) & $37.2 \pm 23.6$ \\
\hline Vitamin D 25-OH (ng/mL) & $18.5 \pm 8.9$ \\
\hline \multicolumn{2}{|l|}{ Lifestyle habits } \\
\hline Sedentary lifestyle (\%) & 42.3 \\
\hline Optimal sleep $6-8 \mathrm{~h}$ per night (\%) & 43.3 \\
\hline Active smoking $(\%)$ & 14.9 \\
\hline Passive smoking (\%) & 43.6 \\
\hline
\end{tabular}

women.

MetS is common in patients who are admitted to the Dialysis Center with a risk of developing complications like cardiovascular disease, but there is still a lack of information regarding the size of problem in Taif, Saudi Arabia. The primary goal of the study was to assess the prevalence of MetS in ESRD patients in the Dialysis Center. The secondary goal of the study was to assess the relationship between MetS, cardiovascular risk, and HD-related outcomes, such as urgent hemodialysis (HD).

\section{Methods}

A cross-sectional study was conducted among ESRD patients who attended the Dialysis Center at King Abdul-Aziz Specialist Hospital, Taif, Saudi Arabia between August 2013 and September 2016. We excluded uncooperative patients, those on peritoneal dialysis, and those younger than 18 years old. Informed consent was obtained from each patient to participate in the study. The data were collected via patient interviews. Demographic data, including age, gender, marital status, and educational level, were collected. Detailed medical histories, including past medical history and HD-related history, were obtained from patients and medical records. Data regarding active and passive smoking habits, lifestyle habits, and sleep were collected. We considered $6-8 \mathrm{~h}$ of sleep per night as an optimal amount of sleep based on the recommendations of the National Sleep Foundation [10]. Physical activity was measured based on the World Health Organization (WHO) recommendations for healthy adults [11]. According to these recommendations, physically inactive patients were considered sedentary.

Anthropometric measurements, including height, dry weight, and waist circumference (WC), were measured. Dry weight was measured in kilograms $(\mathrm{kg})$ after the HD session. Body mass index (BMI) was calculated and categorized based on the WHO classification into underweight $\left(<18.5 \mathrm{~kg} / \mathrm{m}^{2}\right)$, normal weight $\left(18.5-24.9 \mathrm{~kg} / \mathrm{m}^{2}\right)$, overweight $(25-29.9 \mathrm{~kg}$ / $\left.\mathrm{m}^{2}\right)$, or obese $\left(\geq 30 \mathrm{~kg} / \mathrm{m}^{2}\right)$ [12]. WC measurements were done at the approximate midpoint between the lower margin of the last palpable rib and the top of the iliac crest according to the WHO guidelines (STEPS) [13].
We collected data about the different modalities of HD access, including arteriovenous fistulas (AFVs), Permacath, or temporary HD access. Also, the frequency of AVF insertion, duration of AVF use in years, and history of line infection data were collected. Cardiovascular markers were obtained before starting the HD session, including pulse rate, systolic blood pressure, and diastolic blood pressure, which were measured according to the Seventh Report of the Joint National Committee (JNC7) recommendations [14].

Laboratory investigations were recorded from the patient files using the latest results, including total cholesterol (TC), low-density lipoprotein (LDL), high-density lipoprotein (HDL), triglyceride, total serum calcium, serum phosphate, pre- and post-HD creatinine, post-HD urea, parathyroid hormone (PTH), and vitamin D 25-OH (vitamin D) levels. All of biochemical markers are represented as $\mathrm{mg} / \mathrm{dL}$, except for vitamin D (ng/mL) and PTH (pmol/L).

PTH levels were divided into three categories based on the KDOQI Clinical Practice Guidelines for Bone Metabolism and Disease in Chronic Kidney Disease recommendations [15]. We considered PTH at goal if PTH levels ranged from 150 to $300 \mathrm{pg} / \mathrm{mL}$ (16.5 - $33 \mathrm{pmol} / \mathrm{L})$.

We used the IDF definition for MetS diagnosis [16]. Patients with MetS must have central obesity with Middle East-specific values for WC, plus any two of the following: triglycerides $\geq 150 \mathrm{mg} / \mathrm{dL}$ or specific treatment for this lipid abnormality, $\mathrm{HDL}<40 \mathrm{mg} / \mathrm{dL}$ in males and $<50 \mathrm{mg} / \mathrm{dL}$ in females, systolic blood pressure (SBP) $\geq 130$ or diastolic blood pressure $(\mathrm{DBP}) \geq 85 \mathrm{~mm} \mathrm{Hg}$ or HTN-specific treatment, or fasting plasma glucose $(\mathrm{FPG}) \geq 100 \mathrm{mg} / \mathrm{dL}$ or previously diagnosed T2D.

\section{Results}

A total of 241 patients with ESRD on HD were found; these patients were typically married, with a mean age of 48.8 (SD 16) years, mean BMI of 25.6 (SD 8.7$) \mathrm{kg} / \mathrm{m}^{2}$, and mean WC of 92.0 (SD 23.5) (Table 1). Most of the participants had normal BMI (Fig. 1). The most common comorbidities were HTN followed by T2D (Fig. 2). The most commonly prescribed antihypertensive agent was a calcium channel blocker and the least was hydralazine. Most of the patients were on calcium supple- 


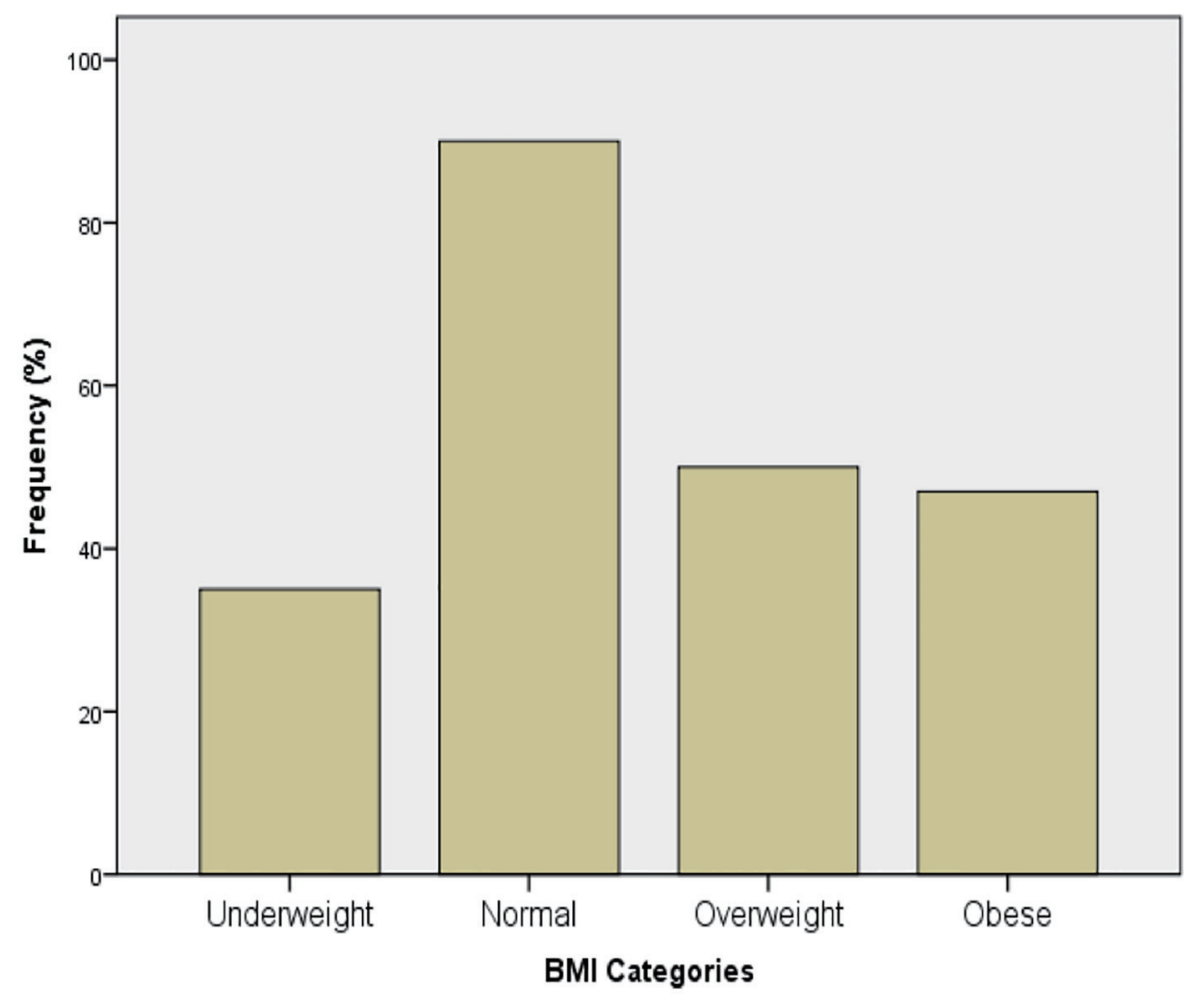

Figure 1. BMI distribution of the whole cohort.

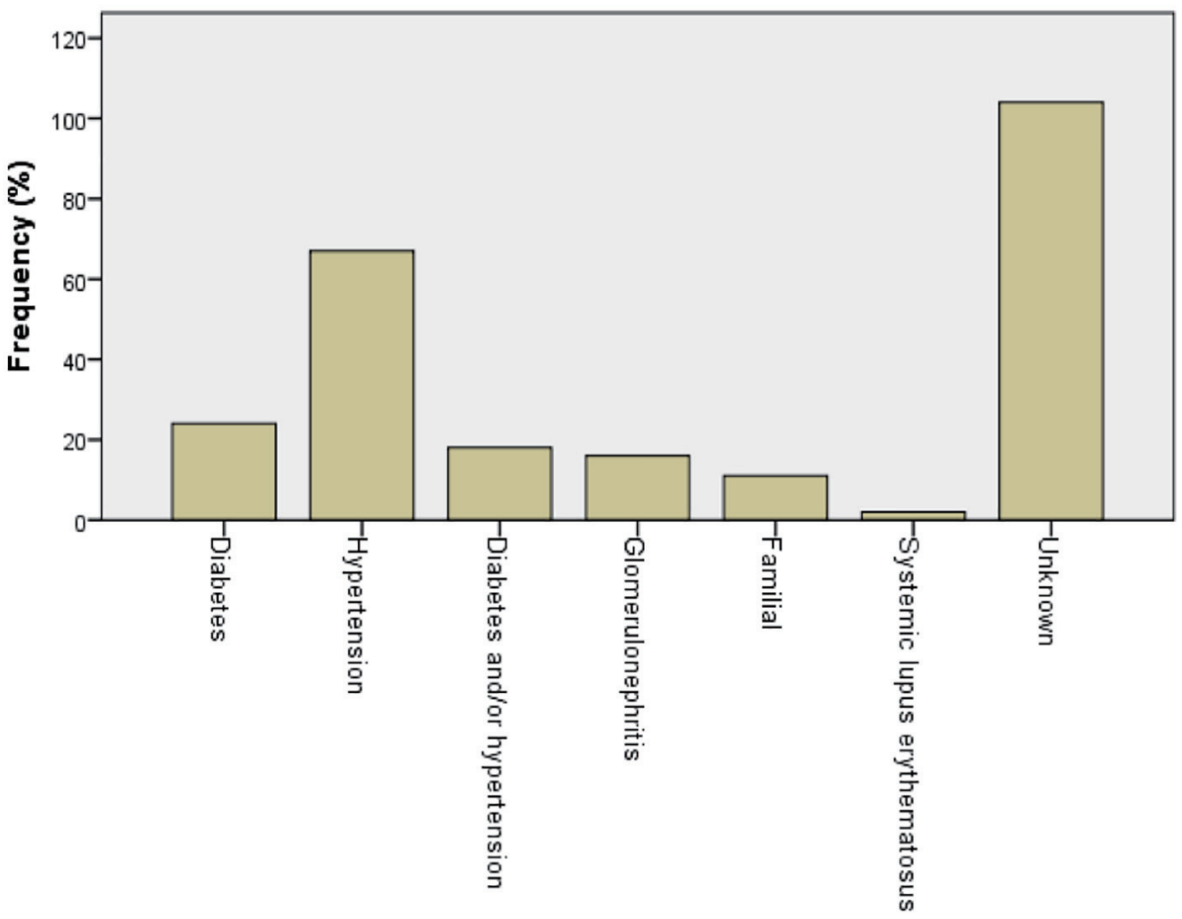

CAUSES OF ESRD

Figure 2. Causes of the ESRD as percentile. 
Table 2. Comparison of the Whole Group Based on the Metabolic Syndrome (MetS) Diagnosis

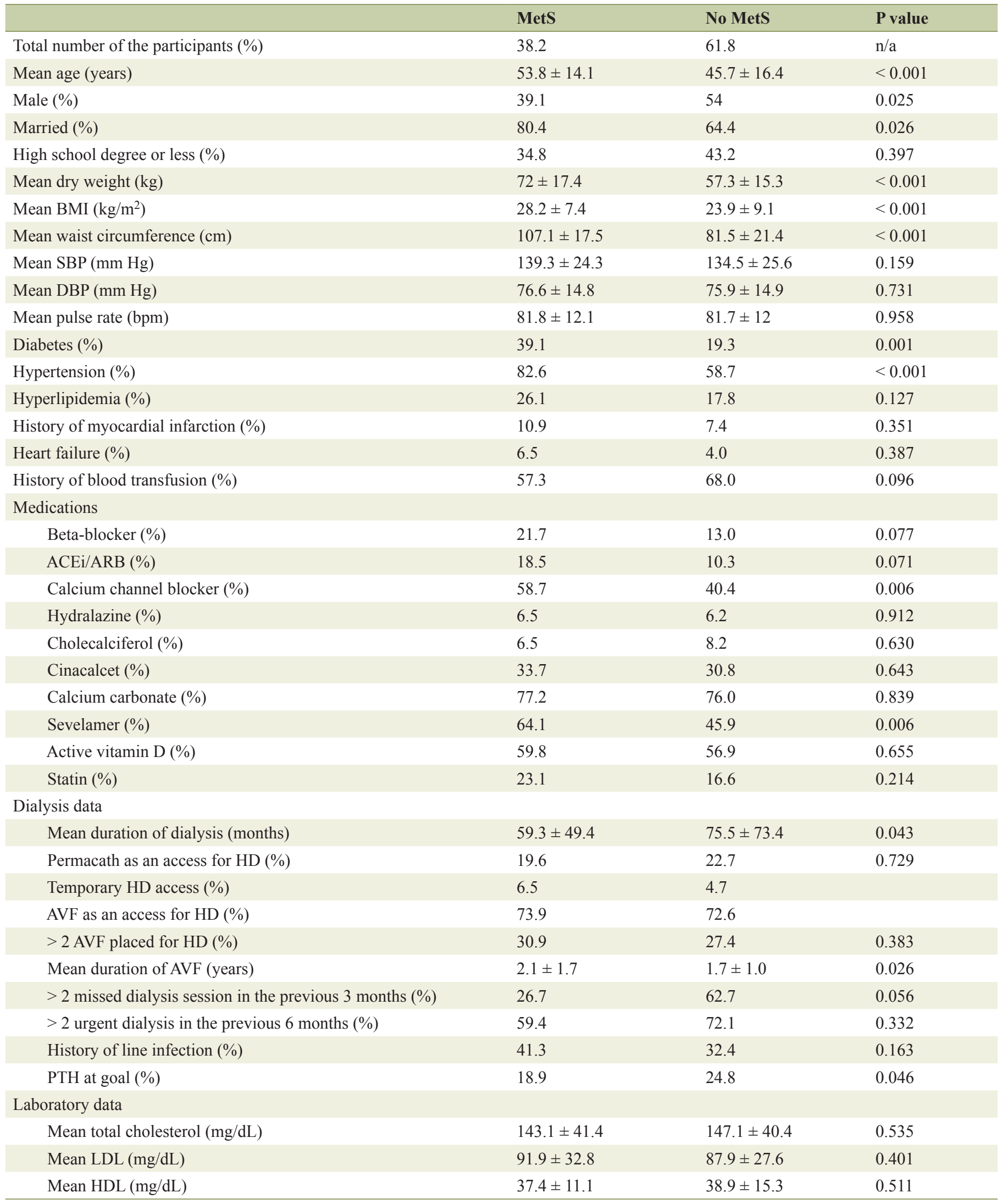


Table 2. Comparison of the Whole Group Based on the Metabolic Syndrome (MetS) Diagnosis - (continued)

\begin{tabular}{|c|c|c|c|}
\hline & MetS & No MetS & P value \\
\hline Mean triglyceride (mg/dL) & $151.9 \pm 100.6$ & $140.2 \pm 109.1$ & 0.485 \\
\hline Mean total $\mathrm{Ca}(\mathrm{mg} / \mathrm{dL})$ & $8.8 \pm 0.9$ & $8.7 \pm 1.3$ & 0.468 \\
\hline Mean pre-HD creatinine (mg/dL) & $13.4 \pm 17.2$ & $16.0 \pm 29.4$ & 0.447 \\
\hline Mean post-HD creatinine (mg/dL) & $6.3 \pm 7.8$ & $5.3 \pm 7.3$ & 0.467 \\
\hline Vitamin D 25-OH (ng/mL) & $18.4 \pm 8.6$ & $18.5 \pm 9.2$ & 0.912 \\
\hline \multicolumn{4}{|l|}{ Lifestyle habits } \\
\hline Sedentary lifestyle (\%) & 44.0 & 41.2 & 0.035 \\
\hline Exercise > 300 min/week (\%) & 3.3 & 14.2 & \\
\hline Optimal sleep $6-8$ h per night (\%) & 45.7 & 41.9 & 0.838 \\
\hline
\end{tabular}

mentation and more than half of them were on sevelamer and active vitamin D supplements.

The mean duration of the HD was 69.3 (SD 65.6) months, with AVF as the most common access for HD. The most common cause for HD was unknown followed by HTN, T2D, and then both HTN and T2D. Half of the patients missed $\geq 2 \mathrm{HD}$ sessions in the previous 3 months and $66.7 \%$ needed $\geq 2$ urgent HD sessions, and one-third of the patients had a history of line infection. Around $43 \%$ of these patients reported sedentary lifestyles, optimal sleep hours, and passive smoking.

Of all the patients, 38.2\% had MetS (Table 2). Compared to those without MetS, those with MetS were more likely to be older $(\mathrm{P}<0.001)$, be female $(\mathrm{P}<0.001)$, be married $(\mathrm{P}<$ $0.001)$, have higher BMI $(\mathrm{P}<0.001)$, have larger $\mathrm{WC}(\mathrm{P}<$ $0.001)$, have T2D $(\mathrm{P}=0.001)$, have HTN $(\mathrm{P}<0.001)$, be on sevelamer $(\mathrm{P}=0.006)$, have shorter HD duration $(\mathrm{P}=0.043)$, have a longer duration since the AVF was placed (P .026), be less likely to have PTH at goal $(\mathrm{P}=0.046)$, have high postHD creatinine levels $(\mathrm{P}=0.010)$, and report sedentary lifestyle habits $(\mathrm{P}=0.035)$.

The adequacy of the HD session was assessed using the urea reduction ratio (URR). Those patients with MetS had a URR of $66.6 \%$ compared to a URR of $71.1 \%$ for those without $\operatorname{MetS}(\mathrm{P}=0.004)$.

Since the study started and until the completion date, there was a total of $41(17 \%)$ deaths among the overall cohort over the 3-year period: 24 without MetS and 17 with MetS. Of those deceased patients with MetS, 12 patients had three MetS criteria and five patients had four MetS criteria.

\section{Discussion}

Our study showed a high prevalence of MetS among patients with ESRD on HD. Although those with MetS have shorter HD durations, they tended to be older, be more likely to have comorbid conditions, and have uncontrolled renal parameters, compared to those without MetS.

In our study, the prevalence of MetS was $38.2 \%$, which is lower than in the other reported study; this is likely because the mean HD duration in our study was 5.8 years [17, 18]. In 2011, a study conducted in Riyadh, Saudi Arabia in ESRD patients on HD showed that $58 \%$ had MetS [19]. Recently, the prevalence of HD for those that have been on HD $<1$ year was $56.25 \%$, compared to $29.7 \%$ for those who had been on HD $>$ 5 years [17].

Regardless of the kidney function and whether the ATP III or IDF criteria were used to diagnose MetS, females and older patients were at higher risk for MetS. Our study showed that patients with MetS were significantly more likely to be older and female than those without MetS. A recent study that used the ATP III criteria in patients without ESRD showed that MetS was associated with older age and female sex [3].

A recent study showed that cinacalcet improved PTH control compared to the usual care [20]. In our study, PTH levels were at goal in $22.5 \%$ of the patients, and those with MetS were less likely to have their PTH at goal despite being more likely to be on cinacalcet; this may be related to the MetS patients' larger WC. Not only was PTH high in those with MetS, but also were the post-HD urea and creatinine levels. A recent study showed that abdominal fat deposition is linked to increased inflammatory markers and subsequently increased mortality [21].

A previous study showed that having a central line and frequent previous hospitalizations were linked to the excess risk of line infection [22]. Our study showed that those with MetS were more likely to have a history of line infection despite having AFV for longer durations, being less likely to have Permacath, and being less likely to need urgent HD; MetS patients were more likely to have T2D.

Our study limitations include the small sample size and studying only a single center. Our strengths include comprehensive medication and laboratory data and HD-related data. A larger prospective study is needed to confirm our findings and 
to assess the long-term consequences of MetS diagnosis and its relation to mortality.

\section{Conclusion}

MetS is common among ESRD and MetS was associated with more comorbidity, worse anthropometric measures at baseline, and worse HD-related outcomes.

\section{Acknowledgments}

The authors are indebted to Mr. Jamaan Almalki, RN, the nursing staff supervisor of the Dialysis Center at the King Abdulaziz Specialist Hospital, Taif, Saudi Arabia, for his support in conducting this research.

\section{Conflicts of Interest}

None.

\section{Funding}

None.

\section{Abbreviations}

ESRD: end-stage renal disease; T2D: type 2 diabetes; DM: diabetes mellitus; HTN: hypertension; MetS: metabolic syndrome; BMI: body mass index; AVF: arteriovenous fistula; IDF: International Diabetes Federation; HD: hemodialysis; ATP III: adult treatment panel III; NHANES: National Health and Nutrition Examination Survey; WHO: World Health Organization; WC: waist circumference; JNC7: The Seventh Report of the Joint National Committee; LDL: low-density lipoprotein; HDL: high-density lipoprotein; PTH: parathyroid hormone; KDOQI: Kidney Disease Outcomes Quality Initiative; URR: urea reduction ratio; SLE: systemic lupus erythematosus

\section{References}

1. Andrassy KM. Comments on 'KDIGO 2012 clinical practice guideline for the evaluation and management of chronic kidney disease'. Kidney Int. 2013;84(3):622-623.

2. Caskey F, Castledine C, Dawnay A, Farrington K, Fogarty D, Fraser S, Kumwenda M, MacPhee I, Sinha MD, Steenkamp R, Williams AJ. UK Renal Registry. Nephron. 2016:132.

3. Alberti KG, Zimmet P, Shaw J, Group IDFETFC. The metabolic syndrome--a new worldwide definition. lancet. 2005;366(9491):1059-1062.

4. Ford ES, Giles WH, Mokdad AH. Increasing prevalence of the metabolic syndrome among U.S. adults. Diabetes Care. 2004;27(10):2444-2449.

5. Townsend RR, Anderson AH, Chen J, Gadebegku CA, Feldman HI, Fink JC, Go AS, et al. Metabolic syndrome, components, and cardiovascular disease prevalence in chronic kidney disease: findings from the Chronic Renal Insufficiency Cohort (CRIC) Study. Am J Nephrol. 2011;33(6):477-484.

6. Shlipak MG, Fried LF, Cushman M, Manolio TA, Peterson D, Stehman-Breen C, Bleyer A, et al. Cardiovascular mortality risk in chronic kidney disease: comparison of traditional and novel risk factors. JAMA. 2005;293(14):1737-1745.

7. Chen J, Muntner P, Hamm LL, Jones DW, Batuman V, Fonseca V, Whelton PK, et al. The metabolic syndrome and chronic kidney disease in U.S. adults. Ann Intern Med. 2004;140(3):167-174.

8. Chang IH, Han JH, Myung SC, Kwak KW, Kim TH, Park SW, Choi NY, et al. Association between metabolic syndrome and chronic kidney disease in the korean population. Nephrology (Carlton). 2009;14(3):321-326.

9. Delavari A, Forouzanfar MH, Alikhani S, Sharifian A, Kelishadi R. First nationwide study of the prevalence of the metabolic syndrome and optimal cutoff points of waist circumference in the Middle East: the national survey of risk factors for noncommunicable diseases of Iran. Diabetes Care. 2009;32(6):1092-1097.

10. Ohayon M, Wickwire EM, Hirshkowitz M, Albert SM, Avidan A, Daly FJ, Dauvilliers Y, et al. National Sleep Foundation's sleep quality recommendations: First Report. Sleep Health. 2017;3(1):6-19.

11. Organization WH. Global recommendations on Physical Activity for health. World Health Organization; 2010.

12. Organization WH. BMI classification. Global Database on Body Mass Index: an Interactive Surveillance Tool for Monitoring Nutrition Transition. Geneva: World Health Organization; 2006.

13. Consultation WE. Waist Circumference and Waist-hip Ratio. Report of a WHO Expert Consultation Geneva. World Health Organization. 2008:8-11.

14. The Seventh Report of the Joint National Committee on Prevention, Detection, Evaluation, and Treatment of High Blood Pressure. Bethesda (MD), 2004.

15. Moe SM, Drueke T, Lameire N, Eknoyan G. Chronic kidney disease-mineral-bone disorder: a new paradigm. Adv Chronic Kidney Dis. 2007;14(1):3-12.

16. Alberti G, Zimmet P, Shaw J, Grundy S. IDF Worldwide Definition of the Metabolic Syndrome. International Diabetes Federation (IDF) Avenue Emile de Mot. 2006;1(9).

17. Tsangalis G, Papaconstantinou S, Kosmadakis G, Valis D, Zerefos N. Prevalence of the metabolic syndrome in hemodialysis. Int J Artif Organs. 2007;30(2):118-123.

18. Tu SF, Chou YC, Sun CA, Hsueh SC, Yang T. The prevalence of metabolic syndrome and factors associated with quality of dialysis among hemodialysis patients in Southern Taiwan. Glob J Health Sci. 2012;4(5):53-62.

19. Al Saran K, Elsayed S, Sabry A, Hamada M. Obesity and metabolic syndrome in hemodialysis patients: single center experience. Saudi J Kidney Dis Transpl. 
2011;22(6):1193-1198.

20. Kalantar-Zadeh K, Block G, McAllister CJ, Humphreys $\mathrm{MH}$, Kopple JD. Appetite and inflammation, nutrition, anemia, and clinical outcome in hemodialysis patients. Am J Clin Nutr. 2004;80(2):299-307.

21. Battistella M, Richardson RM, Bargman JM, Chan CT. Improved parathyroid hormone control by cinacalcet is associated with reduction in darbepoetin requirement in patients with end-stage renal disease. Clin Nephrol. 2011;76(2):99-103.

22. Fram D, Okuno MF, Taminato M, Ponzio V, Manfredi SR, Grothe C, Belasco A, et al. Risk factors for bloodstream infection in patients at a Brazilian hemodialysis center: a case-control study. BMC Infect Dis. 2015;15:158. 